Kansas State University Libraries

New Prairie Press

\title{
SIMPLIFIED DATA ANALYSIS FOR GENERALLY BALANCED BUT MESSY EXPERIMENTAL DESIGNS
}

Richard E. Lund

Follow this and additional works at: https://newprairiepress.org/agstatconference

Part of the Agriculture Commons, and the Applied Statistics Commons

\section{c) (1) () $\Theta$}

This work is licensed under a Creative Commons Attribution-Noncommercial-No Derivative Works 4.0 License.

\section{Recommended Citation}

Lund, Richard E. (1992). "SIMPLIFIED DATA ANALYSIS FOR GENERALLY BALANCED BUT MESSY

EXPERIMENTAL DESIGNS," Conference on Applied Statistics in Agriculture. https://doi.org/10.4148/

2475-7772.1410

This is brought to you for free and open access by the Conferences at New Prairie Press. It has been accepted for inclusion in Conference on Applied Statistics in Agriculture by an authorized administrator of New Prairie Press. For more information, please contact cads@k-state.edu. 


\title{
SIMPLIFIED DATA ANALYSIS FOR GENERALLY BALANCED BUT MESSY EXPERIMENTAL DESIGNS
}

\author{
(Another look at Johnson's 1991 Problem) \\ Richard E. Lund \\ Montana State University \\ Bozeman, MT 59717-0002
}

\begin{abstract}
Johnson posted the essential elements of a 'messy' experimental design and challenged participants at the 1991 KSU Conference on Applied Statistics in Agriculture to provide an analysis. Subsequently, he proposed an analysis using SAS. The experiment was laid out by a soil scientist and involved six classifying factors in an intricate crossing and nesting arrangement which lead to a need to consider eight error terms. My objective at the poster session was to show by live computer demonstration that the analysis can be setup and conducted more easily by use of software applying Wilkinson's methodology.
\end{abstract}

\section{Introduction and Objective}

At the $1991 \mathrm{KSU}$ Conference on Applied Statistics in Agriculture, Johnson posted essential elements of a 'messy' experimental design and challenged participants to provide an appropriate analysis. Subsequently at the meeting, he proposed an analysis using SAS and published details in the conference proceedings (Johnson, 1992).

My objective herein is to demonstrate that the modelling capability of software employing Wilkinson's sweep (1970) together with structural formula proposed by Rogers (1973) provide a more direct and easily constructed analysis. My analytical results do not disagree with Johnson's but rather support the validity of his analysis.

ANOVAs appearing in subsequent displays were produced by MSUSTAT Version 5.10 (Lund, 1992), which implements an algorithm described by Payne and Wilkinson (1977) together with modifications proposed by Heiberger (1980). GENSTAT (Payne, 1987) uses this same methodology and produces identical results. My demonstration using a micro computer at the poster session emphasized use of MSUSTAT because its interactive approach enables alternate models to be considered much more quickly than does GENSTAT's batch approach. (I also consider MSUSTAT to be much more user friendly.) Additional information about MSUSTAT and the Wilkinson methodology follow.

Contribution J-2820 from Montana Agricultural Experiment Station 


\section{The Experimental Design}

The experimental design being considered was based on an experiment set out by a soil scientist which utilized six blocking and treatment factors in an intricate crossing and nesting arrangement. Display 1 illustrates the field plot layout, defines the classifying factors and provides a contrived set of response data labeled YIELD. The three treatment factors are IRRigation (drained, undrained), GYPsum ( $\mathrm{G}+$ for applied, G- for not applied) and previous crop (PC at $\mathrm{F}$ for fallow, $\mathrm{P}$ for perennial alfalfa, $\mathrm{R}$ for 3-year rotation of sesbania-wheat-sesbania, $\mathrm{W}$ for wheat). The function and meaning of the classifying factors REPlication, CB for column-block and RP for row-plot is evident within the plot plan upon recognizing spatial variability in soil characteristics. Response data were generated by SAS with YIELD=RANNOR(1233479). My data are identical to those used by Johnson, enabling comparisons to be made with his analysis.

Johnson says the levels for IRR were randomly assigned. Note that IRR is fully confounded with REP and therefore the its main effects cannot be estimated independently from REP. Its interactions with other factors are estimable. Another peculiarity of the design is that GYP is applied to a strip having one-half PC-plot width and continuing across both REPs (See Display 2). While not commented upon by Johnson, such strip-wise application of a soil amendment occurs frequently in agriculture when it is applied by large heavy field equipment. PC was assigned to 4 $\mathrm{x} 4$ latin squares located within REP.

Each of the several special features of this design by themselves pose no particular difficulty to the data analysis. Competent researchers can justify their use in many situations. This design becomes 'messy' only because so many special features are employed at one time and in such a way as to create numerous error terms.

\section{Wilkinson Methodology}

Wilkinson's methodology is explained fully in Heiberger (1989), extending over 683 pages. I only consider the most obvious attributes here. The methodology requires the model specification to be made by two statements, one for the treatment structure (generally fixed effects) and one for the blocking and error structure (random). Calculations proceed sequentially by strata which are associated with each of the blocking and error terms (reps, blocks, whole-plots, split-plots, measurements, etc.). Individual treatment effects determined from the specification of the treatment structure are assigned algorithmically to appropriate strata.

The first step in the process is to perform a dummy analysis upon internally generated data, but applying the declared model and the treatment codes found in the data set. This dummy analysis determines capability to analyze the data set (ie., checks orthogonality) and develops the calculation scheme (or road map) which subsequently guides the actual analysis. 
Calculations involve a sequence of sweeps, each producing estimates of modelterm effects (model fit) and their associated residuals, upon which sums-of-squares are calculated directly. Calculation dimension and data storage requirements are of order $n$, where $n$ equals the number of observations. Data storage includes only effect estimates, residuals and associated factor-classify codes.

The Wilkinson approach to data storage and calculation can be contrasted with that used for the regression approach employed by SAS GLM. The latter focuses upon sums-of-squares and cross products which have dimension $\mathrm{m} \times \mathrm{m} / 2$, where $\mathrm{m}$ is determined by the number of indicator variables needed for the model, plus one for the dependent.

In the Wilkinson approach, orthogonality among strata and treatment effects are verified by reanalysis sweeps followed with a determination that sums-of-squares have zero value. Reanalysis with appropriate adjustments for design efficiency (determined from the set of classifying codes in conjunction with the stated model) also enables it to handle data from experiments set out as balanced incomplete blocks and designs employing partial confounding of treatment effects. Degrees of freedom for sums-of-squares are determined by an accounting algorithm (rather than submatrix-rank determination used by the regression approach).

The essence of Wilkinson methodology is its capability to develop ANOVAs having correct separation of sums-of-squares and assignment of error mean squares to F-ratios for complicated experimental designs with many blocking and error terms and with a minimum of user effort in model specification. Computer memory requirements are minimal and operation is relatively rapid compared to the regression approach (measured in seconds rather than minutes). Statistical tests for the latter require explicit declaration when the model contains more than one error term. Alternatively, expected mean squares can be analyzed to construct appropriate F-ratios, as was used by Johnson.

One limitation of the Wilkinson methodology is the need for a design attribute called first-order balance (Wilkinson, 1970 and James and Wilkinson, 1971). Regression-based methodology can handle strongly unbalanced data sets and is limited only by estimability requirements for declared treatment effects (based on rank of submatrices).

\section{Symbolic Description of Factorial Models}

MSUSTAT applies algorithm AS 65 (Rogers, 1973) implementing the symbolic description procedure proposed in Wilkinson and Rogers (1973) to interpret userentered model structural statements. Some operator symbols have been altered to bring closer agreement with the more familiar model statements for SAS. While all model specifications herein can be constructed by use of algebraic expressions applying only the operators + and $*$ to factor names, I apply an extended subset of 
the available set to the problem at hand in order to clarify specifications. Defining $\mathrm{A}$ and $\mathrm{B}$ to be names of classifying factors, we have:

\begin{tabular}{|c|c|c|}
\hline+ & $A+B$ & Addition of effects \\
\hline * & compounding & $\begin{array}{l}\text { An interaction when } \\
\text { preceded by } A+B\end{array}$ \\
\hline | & $\begin{array}{l}\text { crossing } \quad A \mid B \\
\text { (see limitations below) }\end{array}$ & $\begin{array}{l}=\mathrm{A}+\mathrm{B}+\mathrm{A}^{*} \mathrm{~B} \\
\text { A short way to declare main } \\
\text { effects and all interactions. }\end{array}$ \\
\hline / & nesting & $\begin{array}{l}\text { A nests } B \text {. That is factor } B \text { is } \\
\text { nested within } A \text {. }\end{array}$ \\
\hline ( ) & $\begin{array}{l}\text { grouping and } \mathrm{A}^{*}(\mathrm{~B}+\mathrm{C}) \\
\text { alteration of precedence }\end{array}$ & $\begin{array}{l}=\mathrm{A}^{*} \mathrm{~B}+\mathrm{A}^{*} \mathrm{C} \quad \text { Can clarify } \\
\text { and shorten expressions. }\end{array}$ \\
\hline
\end{tabular}

\section{Data Analysis}

\subsection{Approach to solution}

Johnson's approach emphasized examination of the eight varying-sized experimental units, determination of the contrasts associated with the various treatment effects, enumeration of all terms in a single model statement and specification of which terms were random in another statement. From application of such, SAS procedure GLM produces output of an ANOVA showing naive F-ratios utilizing the residual as the denominator and then proceeds onward to develop Fratios for correct statistical tests by examination of expected mean squares.

The inherent orthogonality of various aspects of the design enables the analysis to be constructed by aggregating easily visualized components. In a sense I will attack the problem in a way similar to that used by the blind men in the familiar tale of their examination of an elephant. The first felt the trunk and concluded the elephant was like a snake while the second felt the four legs and concluded it was like a forest, etc. But upon successfully aggregating their several independent perceptions, they surely solved their problem in knowing much more about what an elephant is like. 
I proceed by first viewing the design as a randomized complete block (RCB) for the factor GYP and produce the results in Display 2. Next, the design is expanded to a strip-plot upon inclusion of factor IRR to produce Display 3. Factor PC was laid out in two replications of a latin square with IRR confounded with REP (Display 4). Finally, I simply aggregate the orthogonal components from Displays 3 and 4 to produce the complete ANOVA in Display 5. Do I need to worry about any duplications of terms in the model statements? The possibility of non-orthogonality? Which error mean squares should be used as denominators when constructing Fratios to test which treatment effects? No! These are jobs for the Wilkinson methodology. And MSUSTAT displays its solution within seconds so I can try alternate models rapidly.

\subsection{Viewing GYP as being located within a RCB}

An easy way to initiate thinking about the analysis is to blind oneself to all classifying factors assigned horizontally (IRR, REP, CB and PC) in the plot plan and concentrate upon those assigned vertically (GYP and PC). The readily apparent balance in the assignments for the two sets implies orthogonality. The four levels for $\mathrm{RP}$ can be viewed as indexing four blocks each containing two (strips) plots definable by RP*GYP to which the two levels of GYP have been randomly assigned. Stippled patterns illustrate this viewpoint in the plot plan of Display 2. In essence we see an ordinary RCB for which the computer need be told only about the blocking factor and the treatment factor. Specifically, prompts and user-responses (following the = symbol) in declaring the model for MSUSTAT are:

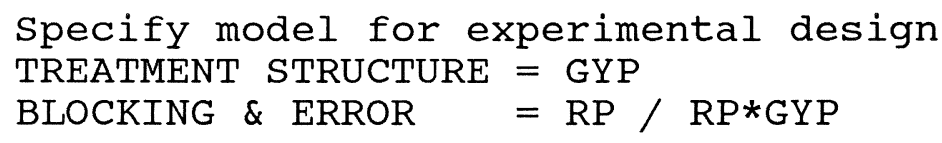

MSUSTAT produces the ANOVA table appearing in the latter part of Display 2. The sum-of-squares for the units stratum (a residual) is related to the multiple measurements across the other classifying factors.

\subsection{Viewing GYP|IRR as a strip-plot design}

Upon enabling the blind man to see the physical layout for REP as well, and telling him that IRR was randomly assigned to an entire REP, he will note that REP and RP are crossed and that new smaller experimental units definable by $\mathrm{REP}^{*} \mathrm{RP} \mathrm{P}^{*} \mathrm{GYP}$ are nested within the earlier strip plots definable by RP*GYP. IRR also is stripped across all levels of RP and thereby GYP so I call this a strip-plot design. The model declaration expands to:

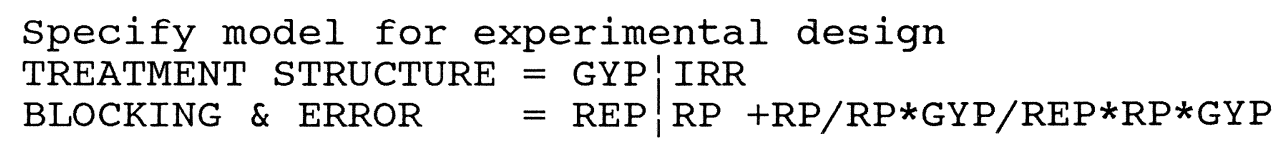


Display 3 shows the essential elements of the layout highlighted with various shadings and the ANOVA produced. The statistical test for the main effect of GYP is identical to that in Display 2. A test for the IRR*GYP interaction is included but none can be provided for the IRR main effect due to confounding with REP.

\subsection{Viewing PC|IRR as a replicated latin square}

Another blind man sees only the assignment of $\mathrm{PC}$ to a pair of latin squares as illustrated in Display 4. He includes REP and RP in the blocking \& error structure of the model to isolate their overall effects as well as $(C B+R P)$ nested within REP for their effects within each square. The experimental units over which $\mathrm{PC}$ was randomly assigned can be defined by $\mathrm{REP} * \mathrm{RP}{ }^{*} \mathrm{CP}$ after nesting within $\mathrm{REP} /(\mathrm{CB}+\mathrm{RP})$ and therefore specifies the error term for main effect $\mathrm{PC}$ and its interaction IRR*PC. The model declaration becomes:

Specify model for experimental design

TREATMENT STRUCTURE = PC|IRR

$\mathrm{BLOCKING} \mathrm{\&} \mathrm{ERROR}=\mathrm{REP}+\mathrm{RP}+\mathrm{REP} /(\mathrm{RP}+\mathrm{CB}) / \mathrm{REP} * \mathrm{RP} * \mathrm{CB}$

which produces the ANOVA in Display 4.

\subsection{Complete analysis by aggregating components}

Our blind men now get together and add together their information about the design. Their model declaration becomes:

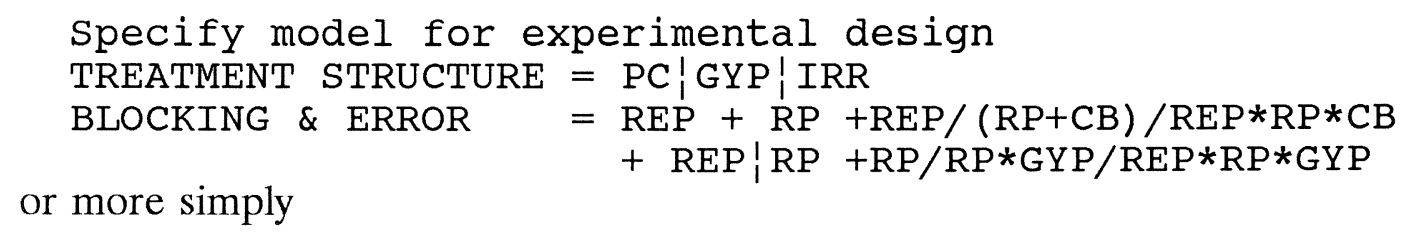

or more simply

BLOCKING \& ERROR = REP $\mid R P+R E P /(C B+R P * C B) / R E P * R P * C B$ $+\mathrm{RP} / \mathrm{RP} * \mathrm{GYP} / \mathrm{REP} * \mathrm{RP} * \mathrm{GYP}$

which finally completes the analysis task, giving the ANOVA in Display 5. Additional output would likely be required. MSUSTAT's display option will list and graph treatment means (optionally with error bars), provide additional tests for contrasts, produce multiple comparisons and plot residuals. The correct error mean squares are accessed from the appropriate stratum. Displays appear within a few seconds of a user's request.

Are the components treated separately by the blind men actually orthogonal? Yes, we verify that by noting equality in the sum-of-squares for various terms as we 
progress from Displays 2, 3 and 4 into 5. Also, MSUSTAT would tell you such and in fact refuse to analyze the data if they were not orthogonal.

\section{Discussion and Conclusions}

1. MSUSTAT and GENSTAT directly display the ANOVA table with all F-ratios correctly calculated. SAS GLM (as run by Johnson) displays an interim ANOVA with correct SS but non-useable F-ratios based upon dividing by the residual. This output is followed by tables of statistics using the variance components to construct the correct tests.

2. MSUSTAT requires defining a new factor named REP associated with the two halves of the plot plan across which IRR was randomized. It does not allow the same factor-effect to appear in both lines of the model statement. GENSTAT is more forgiving and allows the use of IRR in both, but it gives warnings on partial aliasing in some potential models.

3. MSUSTAT produced the finished ANOVA for Display 5 in under three seconds upon one page (running on a Zenith Z-386/20 with a math coprocessor). An equivalent analysis with GLM in SAS using the command file shown in Johnson but without calculations of least squares means required nearly three minutes and produced 150 pages from which the user must still construct a summarizing report or ANOVA with pertinent F-ratios. (Some of this output can possibly be avoided; I do not know how to turn it off.)

4. MSUSTAT and GENSTAT provide missing value estimation capability with direct least squares minimization of residuals within each of the relative multiple strata. Tests generally remain only approximations of the desired tests due to non-consideration of the covariances generated by missing value estimation. Both use the procedure proposed by Healy and Westmacott (1956) with modifications producing faster convergence by Preece (1971). SAS GLM would generally produce only approximately correct tests due to its minimizing only the residual from the model (a single error stratum).

5. The accounting algorithms for determining DF used by MSUSTAT and GENSTAT can fail when a treatment effect is a full alias of another. For example, SAS through matrix manipulation, correctly obtains $12 \mathrm{DF}$ for IRR*RP*PC (error C). MSUSTAT and GENSTAT obtain the correct sumof-squares but incorrectly assign $18 \mathrm{DF}$ to IRR*RP*PC. My proposed model shows error $C$ as the residual in the $R E P * R P * C B$ stratum and obtains the correct DF and sum-of-squares.

6. Two of the error mean squares in the ANOVA of Display 5 have only three degrees of freedom. One may wish to ignore some aspects of the randomization and plot layout and in essence pool some of the strata in order 
to obtain an increase. The rapidity with which the Wilkinson method operates and the emphasis MSUSTAT gives to graphics enables one to interact closely with their data analysis. Several alternate models can be tried in a short time, which may be both a good and bad feature!

\section{About MSUSTAT}

I developed MSUSTAT at Montana State University (MSU) in the mid 1970s to support on-campus instruction in statistical methods. While not its original goal, it quickly found considerable campus-wide use for simpler, smaller, balanced, more standard research data analysis. Most procedures considered in the text Statistical Methods by Snedecor and Cochran are included in its repertoire, plus some additional capability in multivariate, nonparametrics and attribute data analysis.

It was implemented upon microcomputers in 1982-3, somewhat earlier than good commercially distributed statistical software. For example, its availability preceded microcomputer-SAS about three years. MSUSTAT played a critical role in integrating microcomputers into the mainstream of agricultural research here at Montana State University.

While MSUSTAT has been given almost no promotion aimed at distribution off-campus, purchase requests from off-campus have continued at a quite steady rate over the years. Promotion has come from satisfied users and MSU students and staff telling others about it! Surprisingly, about one-half of our distributions are now made for use outside U.S. University staff receiving a temporary foreign assignment often take a copy with them, having confidence that MSUSTAT will always run on whatever (outdated) equipment they may find at the foreign station.

\section{References}

Healy, M. and M. Westmacott (1956), "Missing Values in Experiments Analysed on Automatic Computers," Applied Statistics, 5:203-206.

Heiberger, R. M. (1989), Computation for the Analysis of Variance, John Wiley \& Sons, 683 pages.

Heiberger, R. M. (1980), "An Organizationally Simplified Program for Wilkinson's ANOVA Algorithm (Letter)," Applied Statistics, 29:307-308.

James, A. T. and G. N. Wilkinson (1971), "Factorization of the Residual Operator and Canonical Decomposition of Nonorthogonal Factors in the Analysis of Variance," Biometrika, 58:279-294. 
Lund, R. E. (1992), MSUSTAT Statistical Analysis Package, distributed by the Research and Development Institute Inc., Montana State University, Bozeman, MT 59717-0002.

Payne, R. W. (chairman) and others of Genstat 5 committee (1987), GENSTAT 5 Reference Manual, Clarendon Press, Oxford, 749 pages.

Payne, R. W. and G. N. Wilkinson (1977), "A General Algorithm for Analysis of Variance," Applied Statistics, 26:251-260.

Preece, D. A. (1971), "Iterative Procedures for Missing Values in Experiments," Technometrics, 13:743-753.

Rogers, C. E. (1973), "Interpreting Structure Formula," Alg AS 65, Applied Statistics, 22:414-424.

Snedecor, G. W. and W. G. Cochran (many years and editions), Statistical Methods, Iowa State University Press, Ames, Iowa.

Wilkinson, G. N. (1970), "A General Recursive Procedure for Analysis of Variance," Biometrika, 57:19-46.

Wilkinson, G. N. and C. E. Rogers (1973), "Symbolic Description of Factorial Models for Analysis of Variance," J. Royal Statistical Society, 22:293-299. 


\section{Display 1}

Field plot plan, classify factors and generated data set

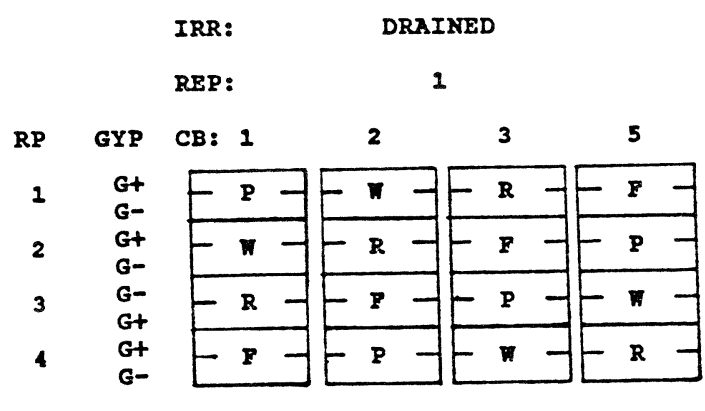

UNDRAINED

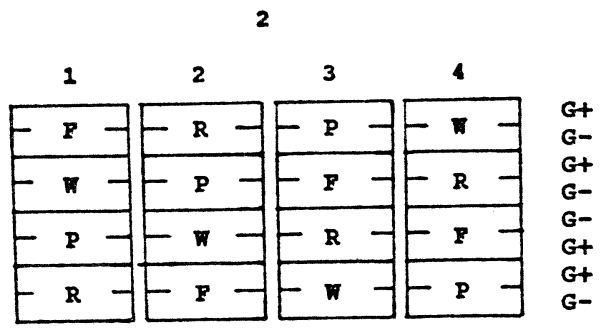

\footnotetext{
REP = replications, 2 levels (left \& right)

$R P=$ row pair, 4 levels $(1,2,3,4$, horizontal across plan)

$\mathrm{CB}=$ column blocks, 4 levels nested within irrigation squares

IRR = irrigation, drained and undrained, confounded with REP

$\mathrm{PC}=$ previous crop, (F-fallow, P-perennial, R-rotation, W-wheat)

GYP = gYpsum, 2 levels (applied G+ and omitted G-)
}

\begin{tabular}{ccccccrr} 
PLT & REP & RP & CB & IRR PC & GYP & YIELD \\
\hdashline 1 & 1 & 1 & 1 & 1 & P & 1 & -0.80164 \\
2 & 1 & 1 & 1 & 1 & P & 2 & 0.20052 \\
3 & 1 & 2 & 1 & 1 & W & 1 & -0.85550 \\
4 & 1 & 2 & 1 & 1 & W & 2 & -0.14015 \\
5 & 1 & 3 & 1 & 1 & R & 1 & -1.05362 \\
6 & 1 & 3 & 1 & 1 & R & 2 & -1.43607 \\
7 & 1 & 4 & 1 & 1 & F & 1 & -1.77614 \\
8 & 1 & 4 & 1 & 1 & F & 2 & 0.83799 \\
9 & 1 & 1 & 2 & 1 & W & 1 & -0.12985 \\
10 & 1 & 1 & 2 & 1 & W & 2 & -1.06477 \\
11 & 1 & 2 & 2 & 1 & R & 1 & -0.07413 \\
12 & 1 & 2 & 2 & 1 & R & 2 & -0.54683 \\
13 & 1 & 3 & 2 & 1 & F & 1 & -0.25569 \\
14 & 1 & 3 & 2 & 1 & F & 2 & 1.94801 \\
15 & 1 & 4 & 2 & 1 & P & 1 & 0.76324 \\
16 & 1 & 4 & 2 & 1 & P & 2 & -1.44499 \\
17 & 1 & 1 & 3 & 1 & R & 1 & 1.30449 \\
18 & 1 & 1 & 3 & 1 & R & 2 & 0.82857 \\
19 & 1 & 2 & 3 & 1 & F & 1 & 1.84350 \\
20 & 1 & 2 & 3 & 1 & F & 2 & -0.45622 \\
21 & 1 & 3 & 3 & 1 & P & 1 & 0.78732 \\
22 & 1 & 3 & 3 & 1 & P & 2 & 0.40438 \\
23 & 1 & 4 & 3 & 1 & W & 1 & 0.86832 \\
24 & 1 & 4 & 3 & 1 & W & 2 & -0.74926 \\
25 & 1 & 1 & 4 & 1 & F & 1 & 0.42360 \\
26 & 1 & 1 & 4 & 1 & F & 2 & -0.62359 \\
27 & 1 & 2 & 4 & 1 & P & 1 & 0.91969 \\
28 & 1 & 2 & 4 & 1 & P & 2 & 0.51675 \\
29 & 1 & 3 & 4 & 1 & W & 1 & -1.87136 \\
30 & 1 & 3 & 4 & 1 & W & 2 & -0.71555 \\
31 & 1 & 4 & 4 & 1 & R & 1 & -1.20186 \\
32 & 1 & 4 & 4 & 1 & R & 2 & 2.38132
\end{tabular}

$\begin{array}{lllll}33 & 2 & 1 & 1 & 2 \\ 34 & 2 & 1 & 1 & 2 \\ 35 & 2 & 2 & 1 & 2 \\ 36 & 2 & 2 & 1 & 2 \\ 37 & 2 & 3 & 1 & 2 \\ 38 & 2 & 3 & 1 & 2 \\ 39 & 2 & 4 & 1 & 2 \\ 40 & 2 & 4 & 1 & 2 \\ 41 & 2 & 1 & 2 & 2 \\ 42 & 2 & 1 & 2 & 2 \\ 43 & 2 & 2 & 2 & 2 \\ 44 & 2 & 2 & 2 & 2 \\ 45 & 2 & 3 & 2 & 2 \\ 46 & 2 & 3 & 2 & 2 \\ 47 & 2 & 4 & 2 & 2 \\ 48 & 2 & 4 & 2 & 2 \\ 49 & 2 & 1 & 3 & 2 \\ 50 & 2 & 1 & 3 & 2 \\ 51 & 2 & 2 & 3 & 2 \\ 52 & 2 & 2 & 3 & 2 \\ 53 & 2 & 3 & 3 & 2 \\ 54 & 2 & 3 & 3 & 2 \\ 55 & 2 & 4 & 3 & 2 \\ 56 & 2 & 4 & 3 & 2 \\ 57 & 2 & 1 & 4 & 2 \\ 58 & 2 & 1 & 4 & 2 \\ 59 & 2 & 2 & 4 & 2 \\ 60 & 2 & 2 & 4 & 2 \\ 61 & 2 & 3 & 4 & 2 \\ 62 & 2 & 3 & 4 & 2 \\ 63 & 2 & 4 & 4 & 2 \\ 64 & 2 & 4 & 4 & 2\end{array}$

$\begin{array}{lrr}\text { F } & 1 & 2.40108 \\ \text { F } & 2 & -1.26272 \\ \text { W } & 1 & 1.36236 \\ \text { W } & 2 & 2.95286 \\ \text { P } & 1 & -0.63343 \\ \text { P } & 2 & 0.70225 \\ \text { R } & 1 & -0.15292 \\ \text { R } & 2 & -0.28423 \\ \text { R } & 1 & 0.77601 \\ \text { R } & 2 & 0.48864 \\ \text { P } & 1 & -1.41652 \\ \text { P } & 2 & -1.34701 \\ \text { W } & 1 & -0.60473 \\ \text { W } & 2 & -0.34978 \\ \text { F } & 1 & -0.13646 \\ \text { F } & 2 & -0.24456 \\ \text { P } & 1 & 0.39682 \\ \text { P } & 2 & 0.90075 \\ \text { F } & 1 & 3.64617 \\ \text { F } & 2 & 0.01453 \\ \text { R } & 1 & -1.99504 \\ \text { R } & 2 & 0.74217 \\ \text { W } & 1 & -2.07992 \\ \text { W } & 2 & 0.95902 \\ \text { W } & 1 & -1.44117 \\ \text { W } & 2 & -0.72310 \\ \text { R } & 1 & 1.34729 \\ R & 2 & 0.82820 \\ F & 1 & -0.36257 \\ \text { F } & 2 & 0.22412 \\ \text { P } & 1 & -0.69294 \\ \text { P } & 2 & 1.65285\end{array}$




\section{Display 2}

\section{Viewing GYP as being located within a RCB}

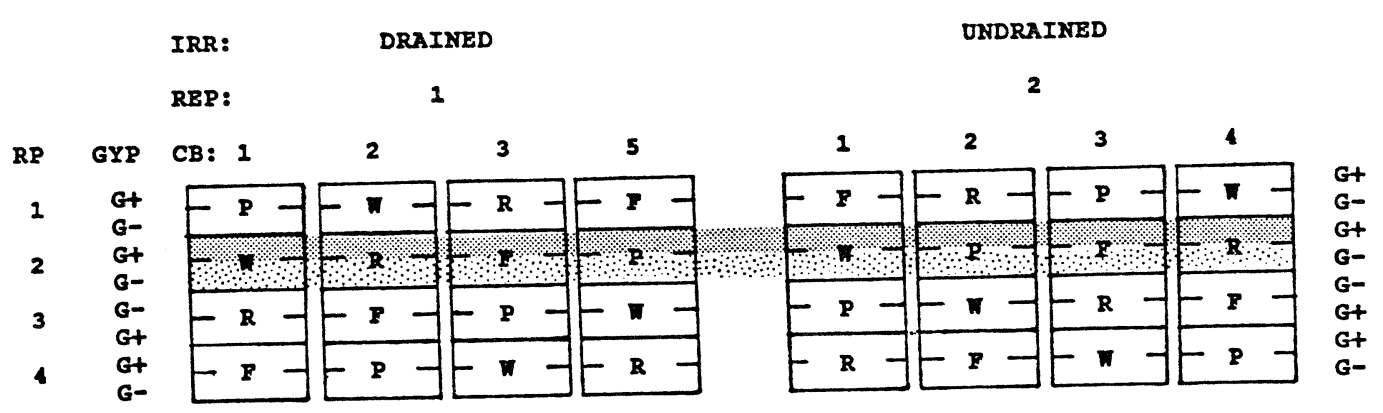

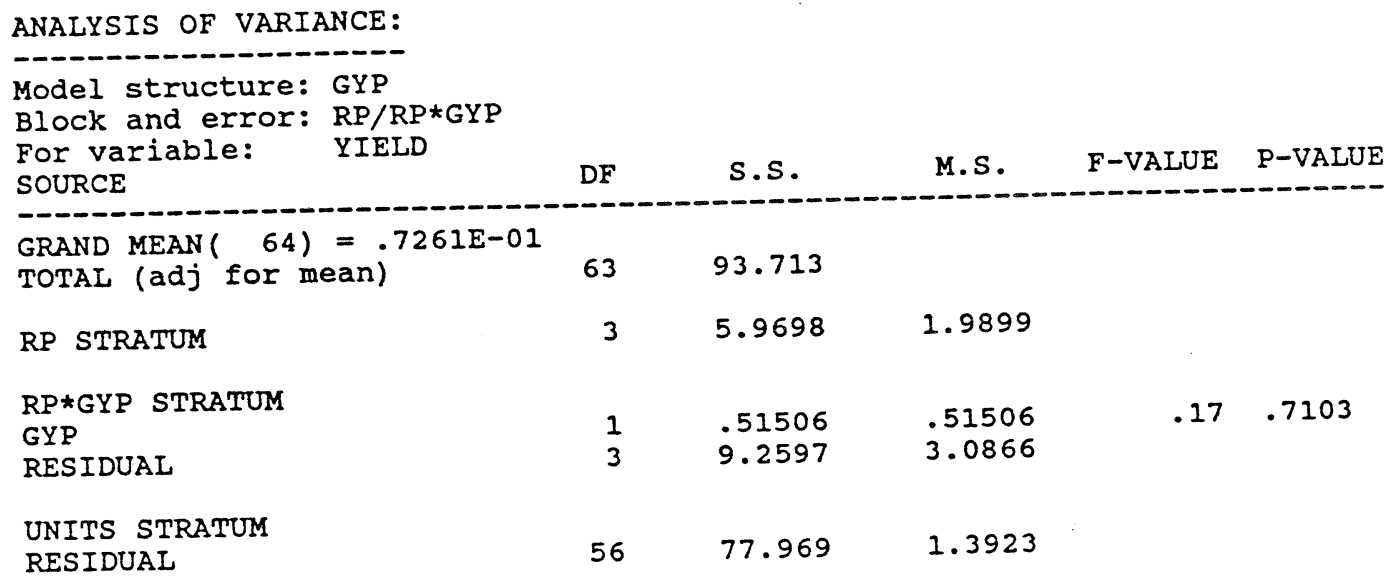




\section{Display 3 \\ Viewing GYP|IRR as a strip-plot design}
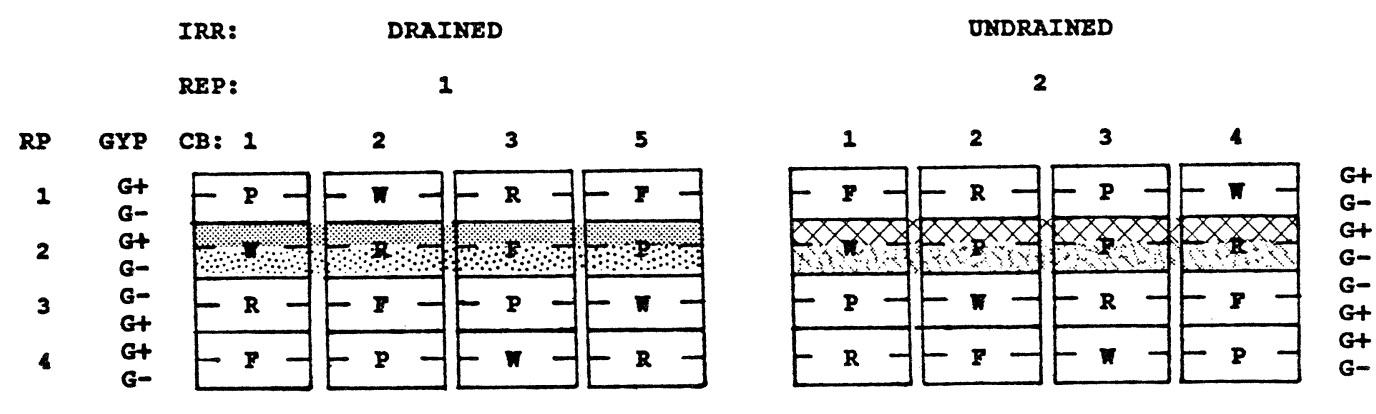

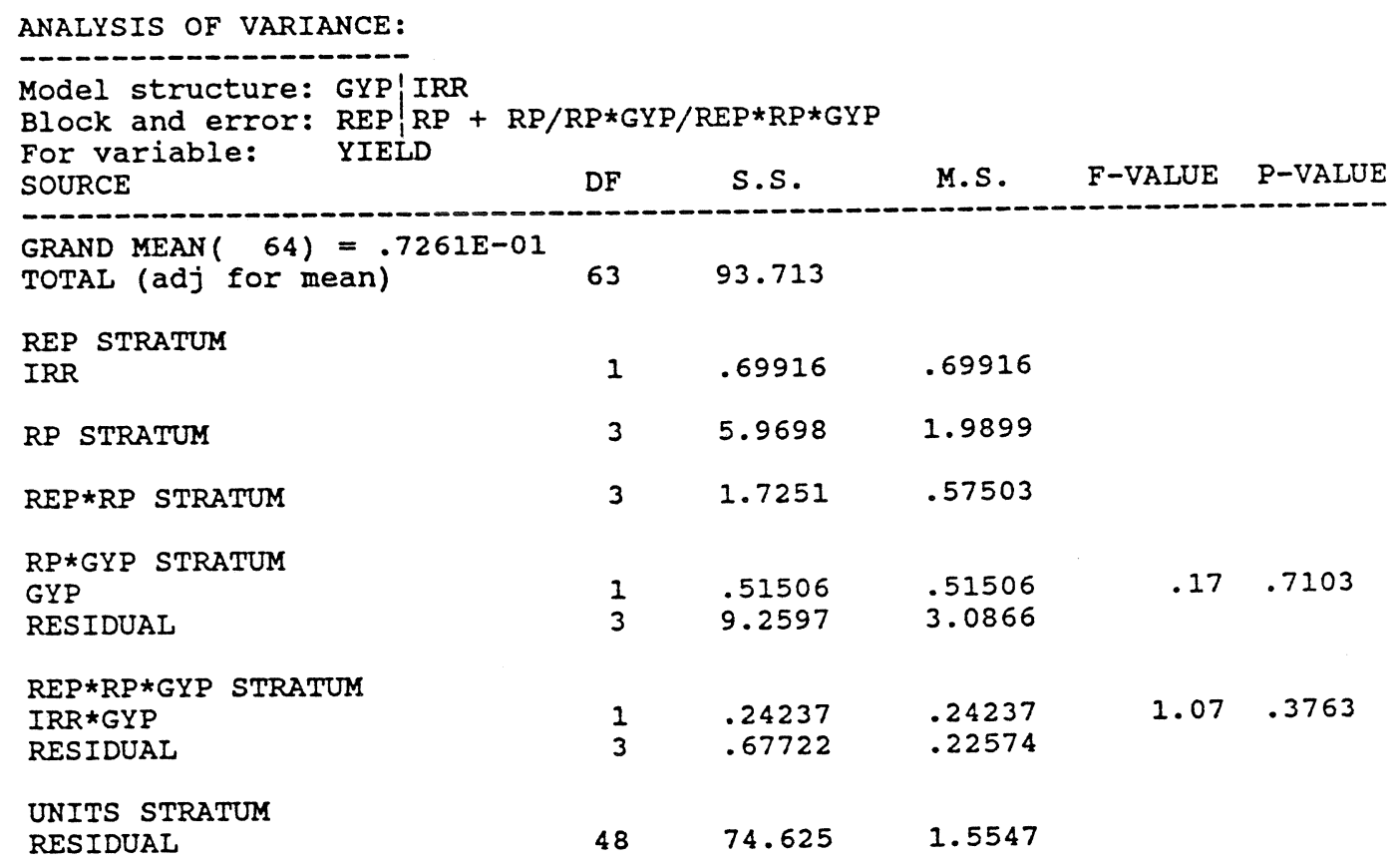




\section{Display 4}

Viewing PC|IRR as a replicated latin square

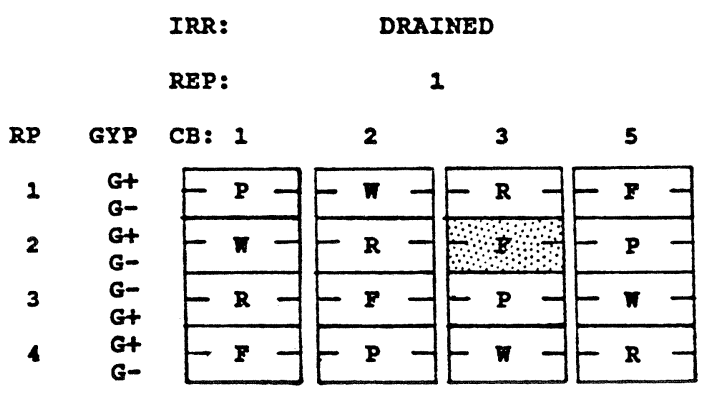

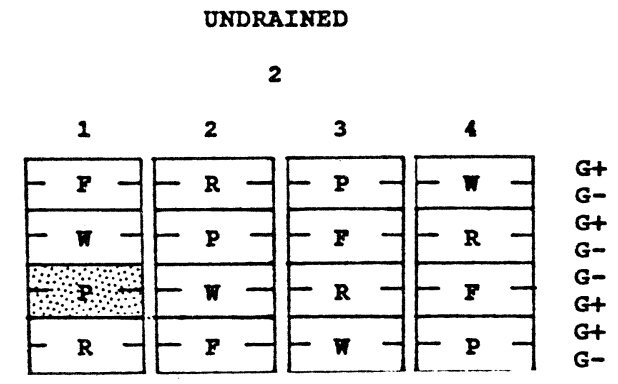

ANALYSIS OF VARIANCE:

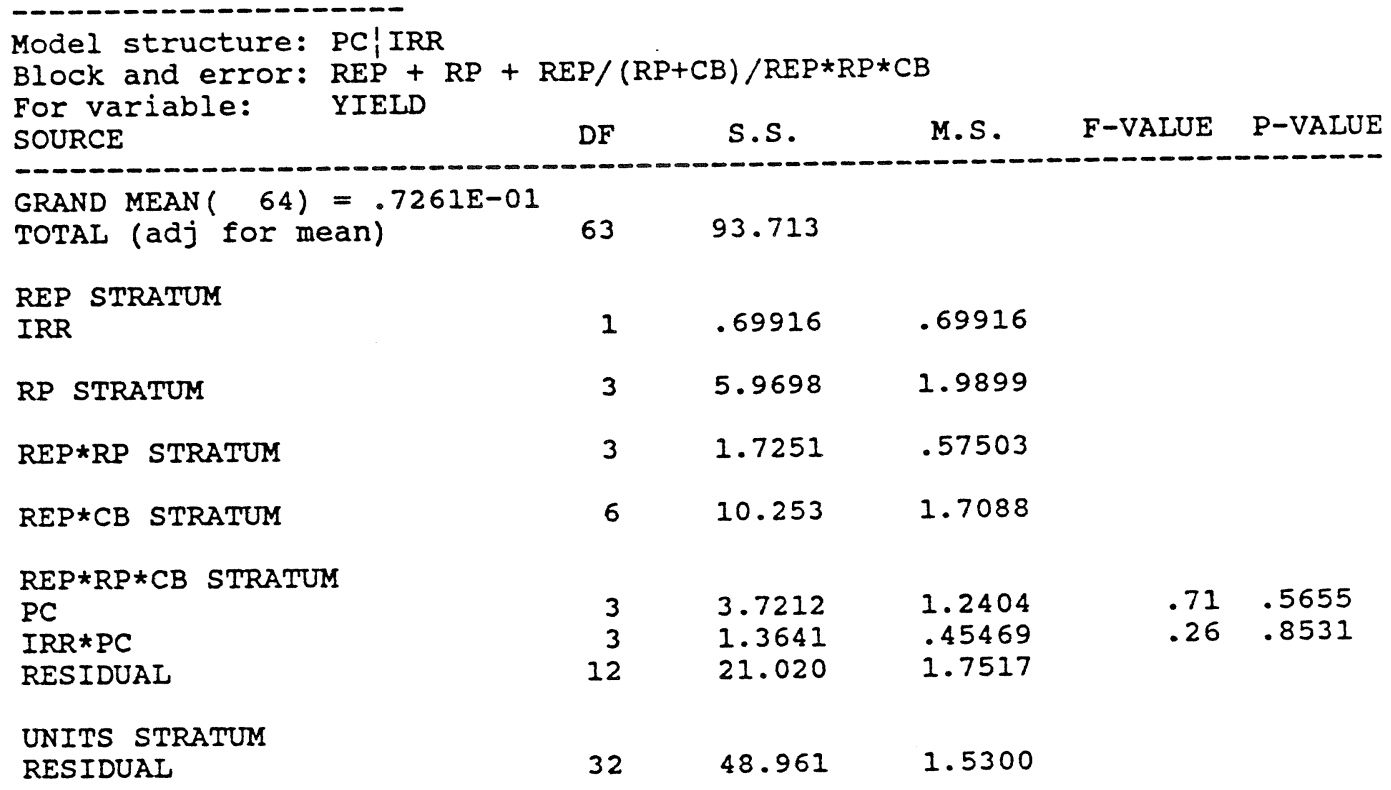




\section{Display 5}

\section{ANOVA for complete analysis}

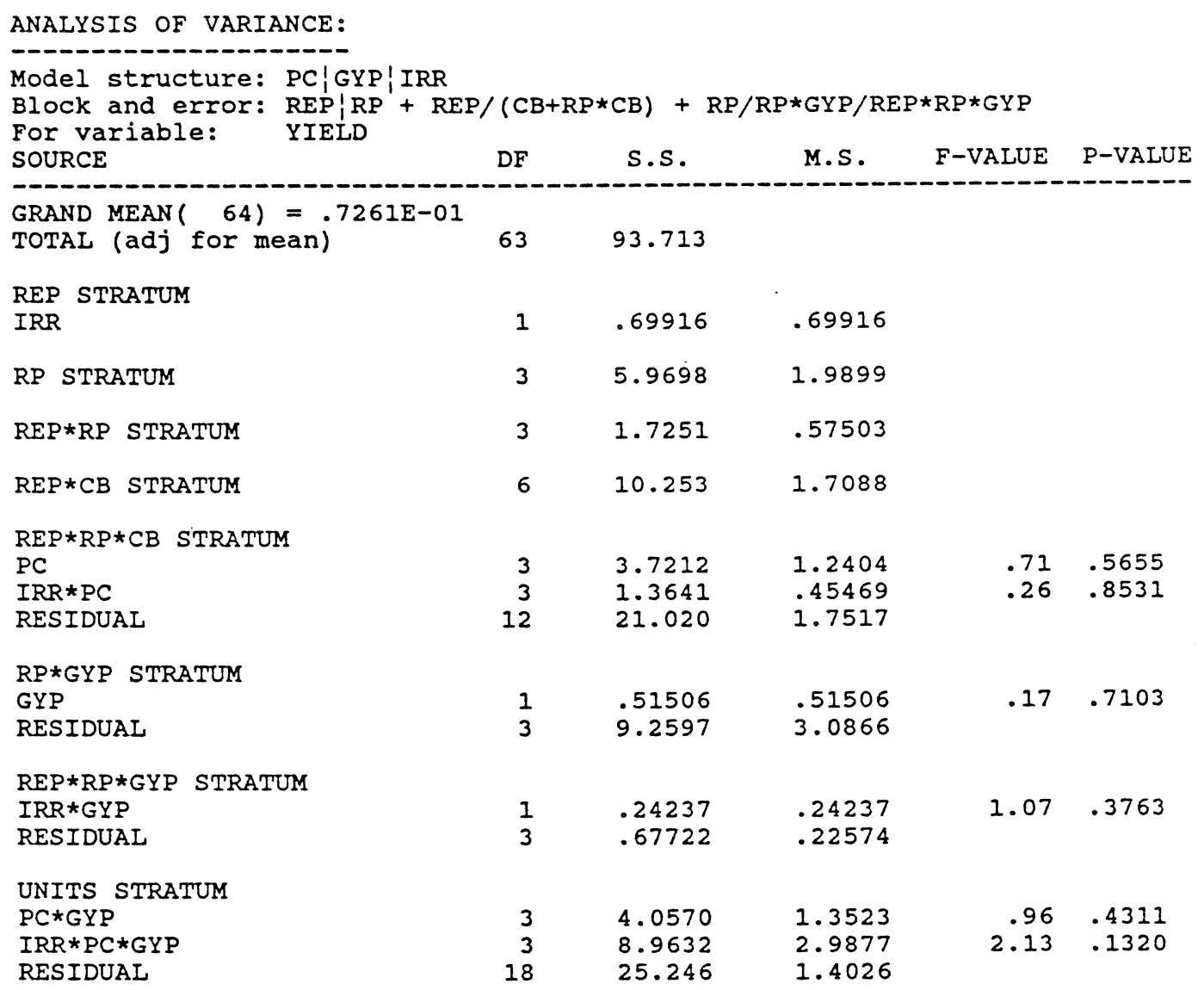

